\title{
A message from the Editor in Chief
}

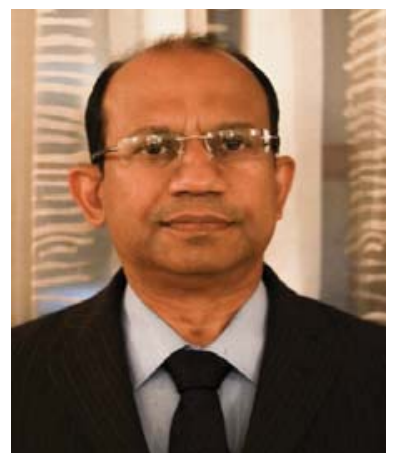

Dear authors, reviewers and readers of the Sri Lanka Journal of Obstetrics and Gynaecology. It is with pleasure I pen this editorial as Editor in Chief of the Sri Lanka Journal of Obstetrics and Gynaecology. At the timing of this writing the whole country is in a state of lock down due to the Corona pandemic. Nevertheless, the responsibility entrusted on me to propagate the objectives of the SLJOG remains uncompromised. The aim is to provide health professionals working in obstetrics and gynaecology with an up-to-date peer reviewed articles to enhance knowledge and new areas of development through research. The current issue (Volume 42, issue 1) of SLJOG consists of salient points of Presidential Address 2020 and challenging subject matter to the scientific oriented practicing obstetrician and gynaecologist. The presidential remarks revisit the progress on reduction of maternal mortality and evaluate remedies to overcome constraints towards further reduction. Gestational diabetes contributes to perinatal morbidity and mortality in South Asia. Controversy surrounds on ideal diagnostic test for diabetes screening in pregnancy. Dr Nalin Rodrigo Oration 2019 sheds light into this dilemma faced by clinicians. Pelvic anatomy related to para rectal spaces are simplified in this issue and it is a delight to read. Heart disease is a leading cause for indirect maternal deaths. Experience on managing cardiac disorders complicating pregnancy is shared for the benefit of readers with practice points. Do's and dont's in managing pre labour rupture of membranes is ill defined. A RCT included in this issue is an eye opener to review further on this controversy. Our main focus will continue to be to publish the highest quality research articles, with a particular emphasis on reliability, safety, current relevance and pragmatic outcomes in research. As Editor-in-Chief, I recognize the value authors place on high-quality and unbiased peer review conducted in a constructive manner. Please bear with the editorial board with all efforts taken to see through the review process. We have implemented rigorous peer review criteria, and this will be reflected in the quality of published articles. I would like to thank our commercial publisher, Ananda Press and their devoted team, for their outstanding work. Thank you all once again for your amazing support and continued efforts aimed at ensuring that the Sri Lanka Journal of Obstetrics and Gynaecology is one of the leading journals in its field. It is my humble duty to acknowledge and extend my profound gratitude to the outgoing editor in chief of SLJOG Prof Ramya Pathiraja. I wish you to stay safe during this pandemic times!

\section{Rukshan C Fernandopulle ${ }^{a}$}

Editor in Chief, SLJOG

Sri Lanka Journal of Obstetrics and Gynaecology 2020; 42: 1

DOI: http://doi.org/10.4038/sljog.v42i1.7924

a Senior Lecturer in Obstetrics and Gynaecology, Faculty of Medical Sciences, University of Sri Jayewardenepura, Sri Lanka. 